\title{
Colour Doppler ultrasound in the management of a case of cranial arteritis
}

\author{
Tom H Williamson, Grant Baxter, Ruby Paul, Gordon N Dutton
}

\begin{abstract}
Colour Doppler ultrasound allows simultaneous B scan and Doppler imaging and can be employed to determine the velocity of blood flow in the vasculature of the eye and orbit. We describe a case of cranial arteritis (giant cell arteritis) in which serial velocimetry recordings were obtained. At one stage in the disease process no blood flow was detectable in the orbit despite previously reliable recordings. This coincided with a deterioration of the clinical state of the patient as signified by recurrent anterior ischaemic optic neuropathy despite controlled symptomatology and erythrocyte sedimentation rate by prednisolone therapy. Subsequent increase in the immunosuppressive therapy was accompanied by a return of blood flow in the orbit. Colour Doppler ultrasound may prove to be a useful examination technique in the diagnosis and management of cranial arteritis.

(Brf Ophthalmol 1992; 76: 690-691)
\end{abstract}

Ophthalmology

TH Williamson

R Paul

G N Dutton

\section{Department of} Radiology, Western Infirmary, Glasgow G11 6NT

G Baxter

Correspondence to:

Tom H Williamson, Tennent Institute of Ophthalmology, Western Infirmary, Glasgow G11 6NT

Accepted for publication 8 June 1992

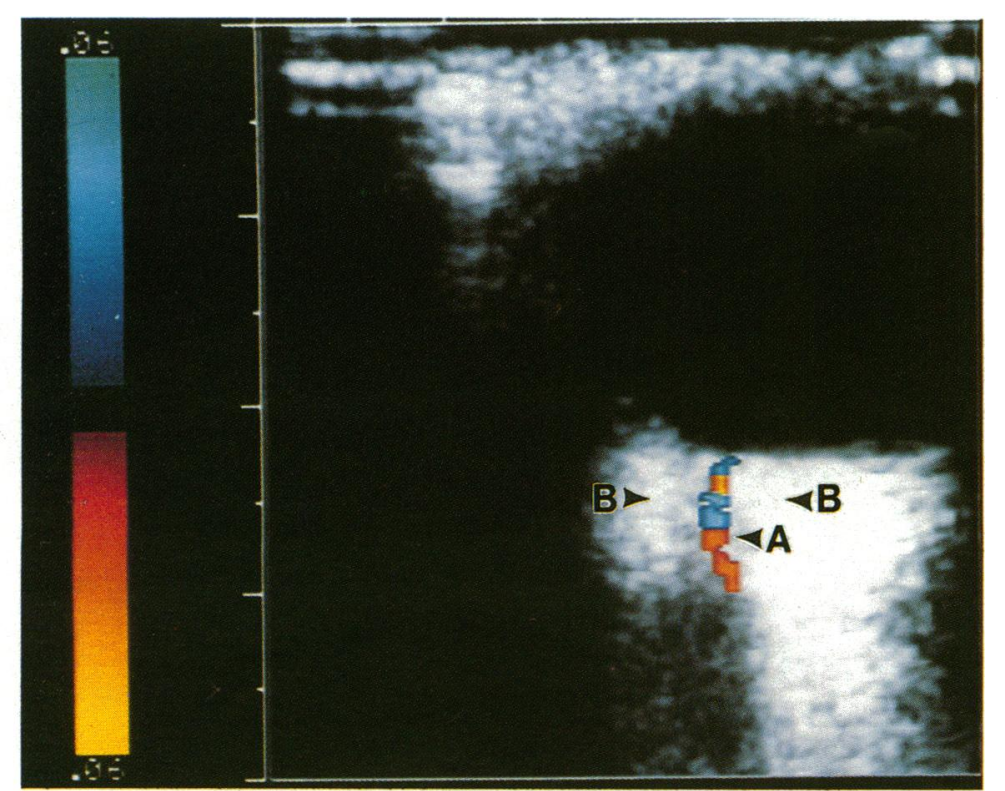

Figure 1 A colour Doppler ultrasound scan of the right eye of this patient within 24 hours of onset of an anterior ischaemic optic neuropathy in this eye. Blood flow (indicated by colour on the scan at arrow A) is apparent in the central retinal artery but is not detectable in the posterior ciliary arteries (arrows $B$ indicate the expected position of these arteries). which directly affected the management of the patient.

\section{Case report}

A 74-year-old female presented with jaw claudication, headache, malaise, and loss of vision in her right eye to counting fingers vision only. She also gave a history of amaurotic attacks in the left eye. Examination showed a pale swollen optic disc on the right side. Her erythrocyte sedimentation rate (ESR) was $132 \mathrm{~mm} /$ hour and a diagnosis of cranial arteritis was suspected and later confirmed by temporal artery biopsy. Systemic prednisolone $80 \mathrm{mg}$ daily was begun.

Colour Doppler velocimetry was performed on the right eye. The examination showed blood flow in the ophthalmic artery and its continuation along the medial orbital wall. At the optic nerve head the central retinal artery was detectable but the posterior ciliary arteries were not (Fig 1). Fluorescein angiography showed a normal retinal arteriovenous time of 3.5 seconds with delayed filling of the superior optic disc (6 seconds after the retinal artery) and non perfusion of the inferior disc margin.

After a period of 2 weeks and while still on 50 mg of prednisolone she developed an altitudinal visual field loss from an incomplete anterior ischaemic optic neuropathy in the left eye. This was despite a reduction of the ESR to $8 \mathrm{~mm} /$ hour and a symptomatic improvement in her clinical status. At the same time, a repeated colour Doppler ultrasound scan of the right eye showed that the blood flow in the ophthalmic artery was no longer detectable, suggesting further occlusion in this orbit presumably owing to

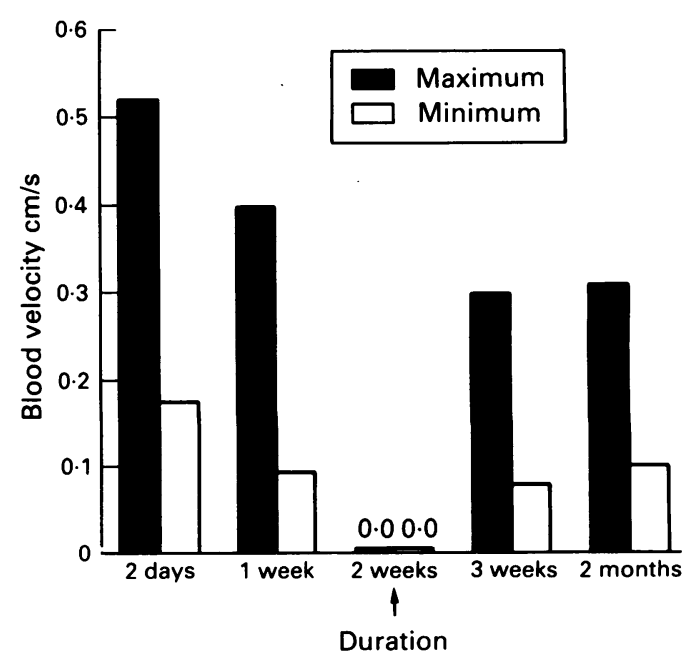

Figure 2 A histogram is shown of five serial measurements of maximum and minimum blood velocity in the right ophthalmic artery. The arrow indicates the time of occurrence of an ischaemic optic neuropathy in the other eye. No colour indices of flow were detected in the right ophthalmic artery. 
further active arteritis (Fig 2). The precarious position of the circulation to the left eye was treated by increasing the dose of prednisolone again to $100 \mathrm{mg}$ (with gradual reduction) and with azathioprine $150 \mathrm{mg} /$ day. A repeated temporal artery biopsy confirmed persistent arterial inflammation.

Two months later, while on $35 \mathrm{mg}$ of prednisolone, the patient developed crush fractures of the thoracic spine secondary to osteoporosis. Further reduction of the steroid therapy was, therefore, desirable. Colour Doppler velocimetry was repeated and showed restoration of blood flow in the right ophthalmic artery. In view of this finding the corticosteroid therapy was reduced and no further vascular mishap occurred. The patient is now on a low maintenance dose of corticosteroid and has suffered no further loss in her vision during the ensuing 6 months.

\section{Discussion}

Cranial arteritis is a condition which often provides the ophthalmologist with diagnostic and therapeutic difficulties. The arteritis is widespread and yet investigation of the circulation is often restricted to examination of the ocular vasculature detectable by fluorescein angiography. Colour Doppler ultrasound has been shown by the authors ${ }^{2}$ and others ${ }^{3}$ to be a useful technique in the examination of orbital blood vessels.

In this case the velocimetry of the orbit varied with the clinical condition of the patient. Detectable loss of flow in the ophthalmic artery of the affected side corresponded with the development of an anterior ischaemic optic neuropathy in the second eye and therefore signified ongoing disease despite a reduction in the ESR and symptoms.

We believe that colour Doppler ultrasound will prove to be useful in the diagnosis and management of cranial arteritis. In this case it was used as an investigative aid to the therapeutic management of the patient.

1 Erickson SJ, Hendrix LE, Massaro BM, Harris GJ Lewandowski MF, Foley WD, et al. Color Doppler flow imaging of the normal and abnormal orbit. Radiology 1989 173: $511-6$.

2 Baxter GM, Williamson TH, MacKillop G, Dutton GN. Color Doppler ultrasound of orbital and optic nerve blood flow: effects of posture and timolol $0.5 \%$. Invest Ophthalmol Vis Sci 1992; 33: 604-10.

3 Lieb WE, Cohen SM, Merton DA, Sheilds JA, Mitchell DG, Goldberg BB. Color Doppler imaging of the eye and orbit, technique and normal anatomy. Arch Ophthalmol 1991; 109: technique

4 Flaharty PM, Leib WE, Sergott RC, Bosley TM, Savino PJ Color Doppler imaging, a new non-invasive technique to diagnose and monitor carotid cavernous sinus fistulas. Arch Ophthalmol 1991; 109: 522-6.

5 Guthoff RF, Berger RW, Winkler P, Helmke K, Chumbley LC. Doppler ultrasonography of malignant melanomas of the uvea. Arch Ophthalmol 1991; 109; 537-41. 